\title{
ENFOQUE FAMILIAR SOBRE CESE DE CONVIVENCIA EN LA JURISPRUDENCIA DEL TRIBUNAL SUPREMO POPULAR DE CUBA
}

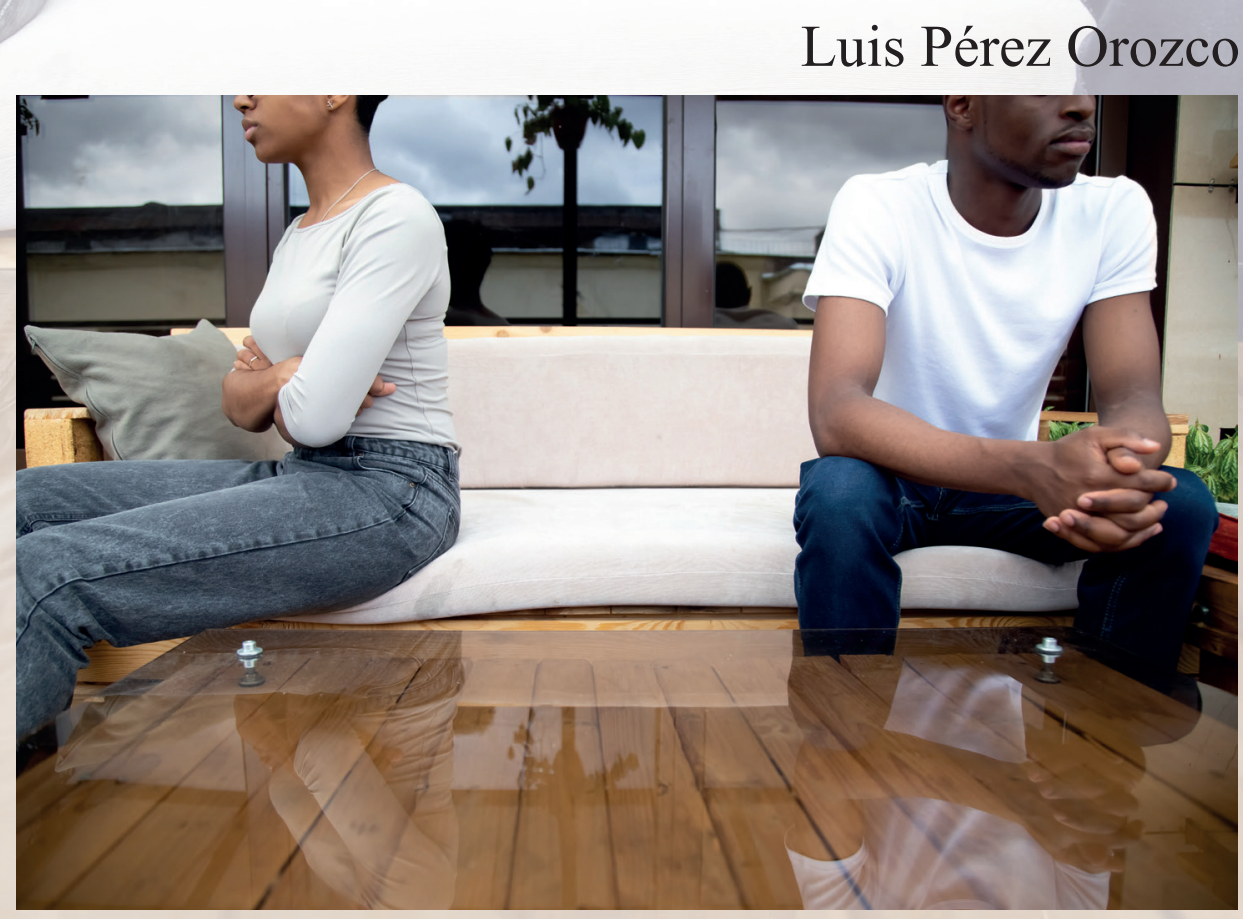





\title{
ENFOQUE FAMILIAR SOBRE CESE DE CONVIVENCIA EN LA JURISPRUDENCIA DEL TRIBUNAL SUPREMO POPULAR DE CUBA*
}

\author{
Luis Pérez Orozco \\ UNIVERSIDAD DE MATANZAS
}

\section{Resumen}

La vivienda tiene diversos significados culturales y apropiaciones subjetivas en la vida familiar. Los conflictos asociados con la permanencia o no de personas en un hogar pugnan con el principio de la familia como núcleo fundamental de la sociedad. En Cuba, quien posea la propiedad de la vivienda podrá declarar el cese de convivencia con determinadas personas. Ante inconformidades de alguna de las partes comienza un proceso que puede terminar en el Tribunal Supremo Popular. Este máximo órgano de justicia ha desarrollado una amplia jurisprudencia al respecto, al ser uno de los procesos más tramitados en el país. Sin embargo, el enfoque familiar de esta problemática en las sentencias ha estado caracterizado por la parvedad. En la actualidad, el Tribunal Supremo debería equilibrar los intereses familiares con los del propietario de la vivienda, mientras se establece una jurisdicción sobre mediación en la familia.

Palabras clave: vivienda, familia, convivencia, jurisprudencia.

El autor: licenciado en Derecho. Asesor jurídico de la Universidad de Matanzas. Correo electrónico: luisperezorozco@yandex.com

Recibido: 15 de agosto de 2018; evaluado: 15 de octubre de 2018; aceptado: 12 de marzo de 2019.

Este artículo forma parte de la línea de investigación sobre el derecho y sus transformaciones en el siglo XXI, del Departamento de Derecho de la Universidad de Matanzas, Cuba. 


\title{
FAMILY APPROACH TO THE CESSATION OF COHABITATION BY THE JURISPRUDENCE OF THE SUPREME PEOPLE'S COURT OF CUBA
}

\author{
Luis Pérez Orozco \\ UNIVERSIDAD DE MATANZAS
}

\begin{abstract}
The concept of Home has different cultural meanings and subjective appropriations in family life. Conflicts associated with people's permanence in a household contrast with the principle of family as the fundamental nucleus of society. In Cuba, whoever owns the property may declare the cessation of cohabitation to certain people. In case of nonconformity, either party may begin a trial that may end in the Supreme People's Court. This highest judicial authority has developed extensive case law on this matter, since it is one of the most frequent lawsuits in the country. However, the family approach to this problem in sentences has been characterized by tenuous pronouncements. Currently, the Supreme People's Court should balance family and owner interests, while establishing a separate family jurisdiction in Cuba.
\end{abstract}

Keywords: housing, family, cohabitation, jurisprudence.

About the author: Attorney. Legal Advisor at the Universidad de Matanzas, Cuba. Email: luisperezorozco@yandex.com

Received: August 15, 2018; reviewed: October 15, 2018; accepted: March 12, 2019 


\section{Introducción}

Los conflictos en el derecho de la familia afectan de forma singular las condiciones de vida de las personas que se ven involucradas en ellos (voluntaria o involuntariamente) y suelen ser de una complejidad que excede en mucho el ámbito jurídico. La dimensión emocional tanto como las relaciones paterno-filiales, las cuestiones económicas e incluso la repercusión social y el impacto en la familia exigen un tratamiento multidisciplinar de estos acontecimientos.

El cauce habitual para procurar dar una solución a estos conflictos no debería ser el litigio judicial de confrontación ante los tribunales, pues para muchas personas supone un trauma de enorme trascendencia que condiciona su vida de forma negativa y perjudica gravemente a los hijos, a las personas que los generan, a sus economías y al desarrollo de sus vidas.

En virtud de los razonamientos expuestos se propuso el siguiente problema jurídico: ¿Las soluciones judiciales al proceso de cese de convivencia en Cuba demuestran la existencia de criterios reiterados en torno a la familia?

En aras de alcanzar el fin investigativo propuesto se utilizaron los siguientes métodos: deductivo-inductivo, que va de lo general (el examen de disposiciones legales nacionales) a lo particular (artículos de esas disposiciones y sentencias dictadas por tribunales cubanos). Además, se recurrió a este cada vez que se aplicó una norma jurídica a la solución de un caso. También se empleó el método análisis-síntesis, para determinar las características más acuciantes del objeto investigado, al hacer una abstracción para segmentar el objeto en aquellas cualidades que lo representan. El método sociológico viabilizó el examen de las disposiciones legales y su interacción con la realidad social y el de análisis histórico resultó muy importante, pues la comprensión total de una determinada situación es inconcebible si no se analiza el precedente y brindó la visión de la transición de la norma y la jurisprudencia.

La discusión científica está orientada a admitir o no un enfoque familiar en las sentencias del máximo órgano judicial cubano, por lo que el autor expone una selección de fragmentos de soluciones casuísticas ofrecidas en recurso de casación de lo dispuesto por los diferentes tribunales provinciales del país. Estas resoluciones judiciales del Tribunal Supremo Popular no tienen como finalidad armonizar la Ley general de la vivienda a las situaciones fácticas y, por tanto, no deben asumirse 
con carácter generalizador, ya que esa función la cumplen las disposiciones del Consejo de Gobierno del propio Tribunal Supremo.

En Cuba, la jurisprudencia no es considerada como fuente formal o directa del derecho, aunque se aboga hoy día por su reconocimiento como tal:

[... la jurisprudencia debe ser reconocida expresamente, en el ordenamiento jurídico cubano, como fuente de Derecho, pues la práctica judicial opera como tal, lo que se evidencia por la utilidad que desempeña en aquel. Dicho reconocimiento contribuye a otorgarle fuerza legal a las líneas de solución del Tribunal Supremo Popular, ante casos similares, y a la labor interpretativa que realiza este órgano, sobre todo frente a las lagunas de la ley, lo que produce unidad de criterio en la aplicación e interpretación del Derecho por los tribunales. ${ }^{1}$

\section{Familia y vivienda: un binomio con matices}

La familia es la célula básica del cuerpo social, la más universal de las instituciones, el agente de socialización por excelencia y la portadora de un patrimonio cultural que deja su impronta en las personas. La institución familiar se entiende según las diversidades culturales y los modelos de cada época. Por lo general, en el seno familiar es en donde se siente mayor seguridad, protección y arropamiento, porque es el refugio frente a los acontecimientos externos, en donde las personas se comportan espontáneamente, quieren y son queridos. En la actualidad es necesario fortalecer la armonía y la paz en los hogares, pues el número de miembros de la familia aumenta cada día; por eso, diversos estudios demuestran distintas acepciones y modelos que surgen en la sociedad sobre el término familia. ${ }^{2}$

Para toda familia, las condiciones de vida representan ese entorno cotidiano en el que vive, actúa y trabaja, las cuales dependerán de las circunstancias sociales, económicas y del espacio físico; todo ello ejerce un gran poder — satisfactorio o no- sobre los miembros que integran el núcleo familiar. Entre estas entidades se encuentra la vivienda, que adquiere un carácter objetivo al ser aceptada como

Raisa María Aguirre Alonso, "La jurisprudencia como fuente de derecho", Justicia y derecho, núm. 26 (junio 2016): 132. http://www.tsp.gob.cu/sites/default/files/revista/documento/26justiciaderechoespecial_0.pdf (acceso mayo 17, 2018).

2 Marisa Herrera, "Distintas formas de organización familiar" en Manual de derecho de las familias, ed. Marisa Herrera (Buenos Aires: Abeledo Perrot, 2015), 17. 
un objeto real con un rol específico. Por eso, la Organización Mundial de la Salud (OMS) ha definido la vivienda como:

[...] un ente facilitador del cumplimiento de un conjunto de funciones específicas para el individuo y/o la familia: proteger de las inclemencias del clima; garantizar la seguridad y protección; facilitar el descanso; permitir el empleo de los sentidos para el ejercicio de las manifestaciones culturales; implementar el almacenamiento; procesamiento y consumo de los alimentos; suministrar los recursos de la higiene personal, doméstica y el saneamiento; favorecer la convalecencia de los enfermos; la atención de los ancianos y minusválidos; el desenvolvimiento de la vida del niño y promover el desarrollo equilibrado de la vida familiar. ${ }^{3}$

Desde otro punto de vista, la vivienda no es solo un producto físico destinado a resolver los problemas del déficit habitacional, sino como apoyo, acompañamiento y fortalecimiento de los procesos de crecimiento interno y social. Para definir una vivienda existen componentes subjetivos que están determinados por la percepción del objeto en sí mismo y por el modo de hacerla, que no siempre es el mismo para todas las personas, los grupos y las sociedades.

Cabría preguntar si la vivienda se podría considerar como la representación de la evolución de los procesos sociales, culturales, psicológicos o políticos mediante los cuales los individuos son capaces de expresar sus necesidades, plantear sus preocupaciones, diseñar estrategias de participación en la toma de decisiones y llevar a cabo acciones políticas, sociales y culturales que les permitan satisfacer o no los requerimientos habitacionales en pro de su salud y la de su familia.

Desde esta perspectiva se resalta la importancia que para una familia tiene la vivienda saludable, pues mejora la calidad de vida de las personas y la calidad ambiental general; no es un secreto que, en la actualidad —-sobre todo en el área iberoamericana—, los problemas de la vivienda son complejos y difíciles de solucionar.

En Cuba se están experimentando los retos de la convivencia intergeneracional en los hogares. Dicha problemática ha sido causada por la situación económica

María del Carmen Rojas, "La vulnerabilidad y el riesgo de la vivienda para la salud humana desde una perspectiva holística. Una revisión necesaria para la gestión de la vivienda saludable", Cuaderno Urbano 4, núm. 4 (diciembre 2004): 156, http://revistas.unne.edu.ar/index.php/crn/article/view/1763/1517 (acceso mayo 17, 2018). 
del país, que ha disminuido la capacidad constructiva del Estado, por los bajos salarios que dificultan la construcción de nuevas viviendas por esfuerzo propio del ciudadano y por el envejecimiento de la población cubana. Los bajos índices de nacimientos y el aplazamiento de la procreación conllevan a la convivencia intergeneracional de extremos: una parte menor de 30 años y otra mayor de 60. Tal tendencia demográfica implica mayor responsabilidad de los jóvenes, quienes asumen el cuidado y la manutención de los ancianos.

Lo cierto es que el Estado ha reaccionado ${ }^{4}$ y, luego de casi dos años desde la aplicación de las normas jurídicas que eliminaron prohibiciones e instituyeron facilidades para compraventa, donación y permuta de viviendas, así como disposiciones que establecieron el otorgamiento de subsidios para construcción o reparación de viviendas a las personas más necesitadas económicamente o afectadas por fenómenos naturales y el otorgamiento de créditos para facilitar la ejecución de acciones constructivas, como resultado del análisis del comportamiento de estas medidas se ha hecho necesario hacer ajustes mediante nuevas políticas aprobadas por el Consejo de Ministros, que en ningún caso prohíben lo ya aprobado.

Entre los objetivos trazados por estas nuevas directrices se encuentran: i) permitir la entrega, a personas naturales, de viviendas que comenzó a construir el Estado y que están paralizadas, con el propósito de que sean concluidas por esfuerzo propio; ii) legalizar y otorgar el derecho perpetuo de superficie a personas afectadas por fenómenos naturales y otros desastres que estén construyendo o reconstruyendo sus viviendas por esfuerzo propio en lugares autorizados, y iii) evitar que los subsidios a personas o las viviendas asignadas por el Estado a precios subsidiados se conviertan en fuente de lucro, en lugar de resolver el problema habitacional. En este punto es útil precisar que las nuevas normas que respaldan jurídicamente la aplicación de estas nuevas políticas están en proceso de elaboración, lo que demuestra que el Estado cubano está trabajando con base en una buena planificación integral de la vivienda que garantice la seguridad de las familias y el futuro de los niños.

Partido Comunista de Cuba, Documentos del 7 mo. congreso del Partido aprobados por el III pleno del Comité Central del PCC el 18 de mayo de 2017 y respaldados por la Asamblea nacional del poder popular el 1 de junio de 2017-I (La Habana: UEB Gráfica, 2017), 12. 


\section{Fundamentos teórico-jurídicos de la propiedad en Cuba. Una especial referencia a la vivienda}

Para la doctrina, la propiedad es el poder directo e inmediato sobre un objeto o bien, que atribuye a su titular la capacidad de disponer de él, sin más limitaciones que las que imponga la ley. Es el derecho real que implica el ejercicio de las facultades jurídicas más amplias que el ordenamiento jurídico concede sobre un bien. Para el jurista Guillermo Cabanellas, la propiedad no es más "que el dominio que un individuo tiene sobre una cosa determinada, con la que puede hacer lo que desee su voluntad". ${ }^{5}$

El propietario tiene acción contra el poseedor de la cosa para reivindicarla, de manera que nadie podrá ser privado de su propiedad sino por autoridad competente y por motivos de utilidad pública, previa siempre la correspondiente indemnización.

El objeto del derecho de propiedad está constituido por todos los bienes susceptibles de apropiación. Para que se cumpla tal condición se requieren tres elementos: i) que el bien sea útil; si no lo fuera, la apropiación carecería de fin; ii) que exista en cantidad limitada, y iii) que sea susceptible de ocupación, pues de otro modo no podrá actuarse.

Se caracteriza por ser el derecho real por excelencia; autónomo; oponible erga omnes, pues los demás están obligados a respetar el dominio del propietario; perpetuo; exclusivo, porque le concede solo al propietario la facultad de usar, gozar y disponer un bien con exclusión de los demás; inviolable; ${ }^{6}$ principal e independiente; elástico, porque el sujeto podría dejar de ejercer algunas de estas facultades que conforman su contenido esencial y no por ello deja de ser titular del bien.

En sentido objetivo, el derecho de propiedad está integrado por tres facultades principales: el uso, el disfrute y la disposición de bienes; en una concepción subjetiva, es la facultad o atribución correspondiente a un sujeto de derecho. Sin embargo, la facultad de disposición no se limita a la enajenación, sino que existen

5 Guillermo Cabanellas, Diccionario enciclopédico de derecho usual, 2 la ed., tomo 3 (Buenos Aires: Heliasta, 1989), 134-135.

6 La Constitución cubana de 1976, con última reforma en 2002, dispone en su Artículo 21 que se garantiza la propiedad personal sobre los ingresos y ahorros procedentes del trabajo propio, sobre la vivienda que se posea con justo título de dominio y los demás bienes y objetos que sirvan para la satisfacción de las necesidades materiales y culturales de la persona. Además, el Artículo 56 estipula que el domicilio es inviolable. Nadie puede penetrar en el ajeno contra la voluntad del morador, salvo en casos previstos por la ley. 
otras variantes de esta facultad, como la destrucción, el abandono, la transformación, la enajenación y el gravamen.

En sus Artículos 15 al 13, la Constitución de la República vigente reconoce seis formas de propiedad: la estatal socialista de todo el pueblo, la de los agricultores pequeños, la de las organizaciones políticas, de masas y sociales, la de las cooperativas, la de las empresas mixtas (así como otras personas jurídicas) y la personal. Su regulación se halla también en el Código Civil (Ley 59 de 1987), desde el Artículo 128 hasta el 160.

La propiedad personal es la manera por la cual los ciudadanos en la sociedad se apropian de los bienes necesarios para la satisfacción de las necesidades individuales, tanto materiales como espirituales y está consignada en el ya mencionado Artículo 21 de la Carta Magna y del 156 al 159 del Código Civil. ${ }^{7}$

Se entienden por bienes de propiedad personal los ingresos y ahorros provenientes del trabajo propio, la vivienda, la casa para descanso, los solares yermos, los medios e instrumentos de trabajo personal o familiar (sin que sean utilizados para la explotación de trabajo ajeno) y los demás bienes adquiridos por cualquier título legal. En relación con determinados bienes de propiedad personal (cuentas de ahorros, bienes artesanales, viviendas, casas para descanso, solares yermos, bienes culturales, automóviles, embarcaciones, armas blancas y de fuego) existen normas especiales que regulan su régimen e imponen límites en cuanto a su disposición inter vivos y mortis causa.

La función social de la propiedad también está presente en la legislación común, cuando el Artículo 129.1 de la Ley sustantiva civil instituye que la propiedad confiere a su titular la posesión, el uso, el disfrute y la disposición de bienes conforme a su destino socioeconómico, expresión esta última que reconoce el deber de los titulares domínicos de ejercer su derecho con ciertas obligaciones y deberes impuestos en

7 En el momento de redactar esta investigación, en Cuba era distribuido un proyecto de Constitución que, luego de aprobarse por la Asamblea Nacional del Poder Popular sería consultado con la ciudadanía entre el 13 de agosto y el 15 de noviembre de 2018 y sometido a referendo. Ese proyecto plantea en el Artículo 82: "Se reconoce el derecho de las personas a una vivienda digna. El Estado trabaja para hacer efectivo este derecho mediante programas de construcción de viviendas, con la participación de entidades y de la población, en correspondencia con las normas del ordenamiento territorial y urbano y las leyes". Asimismo, en el Artículo 21, inciso e), es admitida la propiedad privada que se ejerce sobre determinados medios de producción, de conformidad con lo establecido; a su vez, el inciso f) distingue la propiedad personal como aquella que se ejerce sobre los bienes que, sin constituir medios de producción, contribuyen a la satisfacción de las necesidades materiales y espirituales de su titular. 
la norma, por lo que la propiedad no es ilimitada. Es una fórmula que armoniza los intereses del individuo con los de la sociedad e impide que el ejercicio del propietario menoscabe o afecte en forma alguna el bien común.

La Ley 65 del 23 de diciembre de 1988, Ley general de la vivienda, modificada por el Decreto-Ley 322 del 31 de julio de 2014, dedica su Capítulo V al régimen jurídico de las viviendas de propiedad personal. Al efecto define los derechos y las obligaciones de los propietarios de viviendas. Entre los derechos se pueden citar los siguientes: permuta, donación, compraventa, unificación, división, arrendamiento y cese de convivencia. Como es en este último que se ha centrado la investigación, se procede a su explicación.

\section{Las fases del proceso de cese de convivencia}

Antes de 1959, en Cuba, el cese de convivencia o declaración de conviviente indeseado de un ocupante por su titular era resuelto por los juzgados. Bastaba con su promoción y conocimiento para que se determinara la desocupación en los conocidos procesos de desahucio, practicados por los propietarios sobre los inquilinos que incumplían con el pago de las mensualidades pactadas. Una de las primeras normas del Gobierno revolucionario, la Ley 26 del 26 de enero de 1959, suspendió los lanzamientos dispuestos por el juzgado en los juicios de desahucios pendientes de ejecución y fueron prorrogados por la Ley 503 de agosto de 1959. A partir del Acuerdo 113 del 24 de julio de 1962 del Consejo Superior de la Reforma Urbana (RU), complementado por las Instrucciones de 4 de febrero de 1963, comenzaron a regularse los conocidos procesos contra convivientes u ocupantes.

Según la letra de aquel Acuerdo, estos procesos podían ser dirigidos contra cualquier ocupante que conviviera con otros en un mismo inmueble y tendiera a perturbarlos o despojarlos de sus derechos, en las Oficinas Regionales de la Reforma Urbana, con audiencia de las partes y prácticas de pruebas. Fue la Ley de reforma urbana, promulgada el 14 de octubre de 1960, la normativa que abrió la posibilidad de que los inquilinos de arrendamientos pudieran adquirir la propiedad de la vivienda que ocupaban mediante el pago mensual de la misma cantidad que pagaban como renta, durante un número de años no menor que cinco ni mayor que veinte, según la fecha de construcción. Proscribió a su vez el arrendamiento de inmuebles como cualquier otro negocio que implicara la cesión total o parcial de un inmueble urbano. $\mathrm{Al}$ amparo de esta Ley se convirtieron en propietarias cerca de 200.000 familias, pero según la posterior Ley 1033 de 1962, la morosidad en el pago de la renta por 
más de tres meses era causa para perder el derecho de adquirir la propiedad y el ocupante quedaba como usufructuario.

Los procesos seguidos en este entonces para cesar la convivencia e interrumpir la ocupación de la vivienda por las personas no deseadas por los titulares eran sustanciados mediante la Oficina Regional cuyo fallo, por virtud de lo dispuesto en la RU-7 del 1 de marzo de 1968, era impugnable ante la Comisión de recursos de alzada correspondientes, la cual podía señalar inclusive el traslado del conviviente a una habitación, aunque esta medida extrema solo fue aplicada con carácter excepcional. Más adelante, la RU-15 del 25 de junio de 1973 abrió la posibilidad de cesar la convivencia u ocupación legal temporal, tal como lo definía, por el propietario u ocupante legal principal y se hacía efectiva por medio de las Oficinas Regionales con la declaración de ocupantes ilegales de aquellas personas. Fue esta la primera vez que se utilizó el término para definir el uso de un bien inmueble, que podría resultar temporal, legal o ilegal.

La Ley 48 de 1985 estableció la transferencia de la propiedad a favor de estos "usufructuarios onerosos" y legalizó la ocupación de otro numeroso grupo de ocupantes. En 1984 eran unos 480.000 nuevos usufructuarios al amparo de esta nueva Ley, incluidos los que habían construido en terreno estatal, adecuado una vivienda, un cuarto o una habitación inhabitable y otros supuestos, a los que llamó "ocupantes legítimos" con derecho a transferir la propiedad. Esta vez se utilizó el término para designar el derecho real contraído sobre un bien y se mantuvo hasta la entrada en vigor de la actual Ley general de la vivienda el 23 de diciembre de 1988, en la que se reconocen otros tipos de ocupación. ${ }^{8}$

\subsection{La regulación del cese de convivencia en la Ley general de la vivienda y su trascendencia}

Con la entrada en vigor de la Ley 48 de 1984, se dispuso en su Artículo 64 que el propietario definiría las personas que convivirían y sus excepciones y darían por terminada la convivencia cuando estimara pertinente, sin necesidad de una

8 Erick Ortega García, "La ocupación de viviendas como categoría legal, a partir de las modificaciones introducidas en el derecho inmobiliario cubano", Misión jurídica, núm. 7 (enero-diciembre 2014): 90, https:// www.revistamisionjuridica.com/wp-content/uploads/2017/03/La-ocupaci\%C3\%B3n-de-viviendas-comocategor\%C3\%ADa-legal-a-partir-de-las-modificaciones-introducidas-en-el-derecho-inmobiliario-cubano. pdf (acceso mayo 15, 2018). 
declaración administrativa o judicial; se exceptúan los ascendientes y descendientes, porque se encuentran en un estatus diferenciado por la ley.

Si el conviviente no abandonara la vivienda, el propietario podrá solicitar a la Dirección Municipal de la Vivienda la emisión de resolución para conminarlo a hacerlo en un término de noventa días naturales posteriores a la notificación de la resolución; transcurrido ese tiempo, se recabará a la Policía Nacional Revolucionaria para que proceda a su extracción. Contra aquella Resolución no cabrá recurso ni en lo judicial ni en lo administrativo. Pese a lo regulado en ese artículo, la Disposición transitoria décimo tercera instituyó que a los convivientes actuales (o sea, en el momento de su entrada en vigor) no se les aplica dicha medida hasta el 1 de enero de 1986. Además, la Disposición especial décimo quinta autorizaba el recurso de revisión ante el Instituto Nacional de la Vivienda.

En la Ley 65 de 1988, Ley general de la vivienda, se concibieron principios importantes para el propietario y para sus convivientes. El Capítulo V, denominado "Régimen jurídico de las viviendas de propiedad personal", Sección Primera, "Derechos y obligaciones de los propietarios de viviendas", regula en el Artículo 64 el primer derecho reconocido a los propietarios, del que resulta su facultad para determinar los convivientes y dar por terminada la convivencia en cualquier momento, sin necesidad de una declaración administrativa o judicial, de forma que "la acción de cese de convivencia ejercitada resulta de carácter personal y exclusivo de los titulares de inmuebles".

Reconoce como conviviente a un tipo de ocupación desarrollada por las personas que estén permanentemente en una vivienda con la anuencia del propietario, aunque no tengan algún grado de parentesco. Habrá personas que, sin hallarse en casos de ocupación ilegal a los que se refiere la Ley, residen con el propietario y forman parte del grupo familiar que ocupa la vivienda, aunque no tengan relación de parentesco alguno con el propietario. El requisito indispensable para ser considerado conviviente del inmueble en cuestión es la anuencia del propietario. Así, "la calidad de propietario lleva implícita la posesión del bien de que se trate y el hecho de no residir en la vivienda no invalida el ejercicio de la acción para la aplicación del citado artículo 64 "10 $\mathrm{y}$ "el derecho a dar por terminada la convivencia de cualquier

República de Cuba, Tribunal Supremo Popular, Sentencia 324 del 10 de abril de 2008, Sala de lo civil y lo administrativo, M. P. Orlando González García.

10 República de Cuba, Tribunal Supremo Popular, Sentencia 1244 del 10 de diciembre de 2010, Sala de lo civil y lo administrativo, M. P. Carlos Manuel Díaz Tenreiro. 
persona en su inmueble, se evidencia su falta de legitimación activa para la acción que ejercita, pues tampoco puede equipararse tal carácter al de arrendatario ni de usufructuario gratuito". ${ }^{11}$

En el caso de los ocupantes ilegales, se aclara que están fuera de la ley o al margen de ella, es decir, su ocupación es contraria a derecho y sancionada en la vía administrativa con las medidas que la ley dispone, pues el interés en pugna es contra el Estado. Mientras, los convivientes llegan a la vivienda con la anuencia del titular. Cuando se da por terminada la convivencia, hay dos intereses particulares en pugna. En este sentido, la autorización expresa o tácita, indefinida o temporal, para permanecer en una vivienda otorgada por el propietario no genera derecho alguno a favor del beneficiario. Dados estos preceptos jurídicos, a los convivientes se les aplica un tratamiento diferente al de los ilegales: el embargo de ingresos y no la extracción.

\subsubsection{Los convivientes especialmente protegidos}

El Artículo 65 de la Ley general de la vivienda instituye el régimen de los convivientes especialmente protegidos, contra los que el propietario no podrá ejercer el cese de convivencia. Con dicho precepto se limita la facultad del propietario de dar por terminada la convivencia en casos excepcionales y tales convivientes se constituyen como ocupantes, sin que ello signifique igual derecho que el titular ni una posible oposición a los actos de dominio ejercidos por este, siempre que no contradigan la ley. Define cinco supuestos que enmarcan situaciones en cuyos casos los convivientes no podrán ser cesados por el propietario interesado: i) sus ascendientes; ii) sus descendientes, ${ }^{12}$ iii) madre con uno o más hijos habidos en el matrimonio, formalizado o no, con el propietario, siempre que ella tenga la guarda y el cuidado de los hijos; iv) madre con uno o más hijos menores que llevan tres o más años ocupando la vivienda: ${ }^{13} \mathrm{v}$ ) ancianos que llevan tres o más años ocupando la vivienda (en estos tres últimos supuestos, siempre que no tengan otro lugar de residencia) ${ }^{14}$ y vi) cualquier otro caso que, a juicio de la autoridad competente,

11 República de Cuba, Tribunal Supremo Popular, Sentencia 1449 del 24 de noviembre de 2014, Sala de lo civil y lo administrativo, M. P. Carlos Manuel Díaz Tenreiro.

12 República de Cuba, Tribunal Supremo Popular, Sentencia 30 del 15 de octubre de 2012, Sala de lo civil y lo administrativo, M. P. Orlando González García.

13 República de Cuba, Tribunal Supremo Popular, Sentencia 147 del 28 de febrero de 2005, Sala de lo civil y lo administrativo, M. P. Isabel Arredondo Suárez.

14 República de Cuba, Tribunal Supremo Popular, Sentencia 555 del 17 de mayo de 2011, Sala de lo civil y lo administrativo, M. P. Orlando González García; Sentencia 384 del 28 de abril del 2000, M. P. Marta Acosta Ricart. 
constituya una manifiesta injusticia o un acto inhumano. ${ }^{15}$ Se concede un arbitrio administrativo para valorar algunos eventos que bien pudieran resultar similares a los que recoge la Disposición transitoria tercera de la Ley general de la vivienda, a efectos de fundamentar su aplicación.

A su vez, la Disposición transitoria tercera expresa que la facultad concedida al propietario por el Artículo 64 no podrá ejercerse contra las personas que, en el momento de su promulgación, se hallen en alguna de las situaciones siguientes: i) conviven en el inmueble desde antes del 14 de octubre de 1960; ii) convivientes que lo fueron del propietario anterior y que, por fallecimiento o salida del país, la titularidad le fue transmitida a otra persona; ${ }^{16}$ iii) personas que han construido ampliaciones en la vivienda con autorización de su propietario, ${ }^{17}$ iv) los que han contribuido en forma efectiva a la adquisición de la vivienda, ${ }^{18}$ como los casos de permutas o entregas de dos casas por una, personas que pagaron el precio de la vivienda porque el adquirente era menor o insolvente y otros análogos que decida el presidente del Instituto Nacional de la Vivienda, y v) los que han contribuido en forma efectiva a la reconstrucción de la vivienda, como los casos de viviendas en mal estado, de propiedad personal que son reconstruidas por los convivientes del

15 "[...] debe también evaluarse para una correcta solución del conflicto, las reglas de especial protección que contiene el artículo sesenta y cinco de la propia ley citada, por lo cual, en el caso en examen, debe apreciarse en favor de los ocupantes, en armonía con lo anteriormente señalado, la pleca quinta del último precepto mencionado, en el sentido de que disponer el cese de convivencia de las personas que ocupan el inmueble resulta un acto injusto, toda vez que no tienen lugar a donde ir a residir, estuvieron al cuidado del propietario hasta su fallecimiento y tienen descendientes menores de edad formando parte de su núcleo familiar, lo que los coloca en un estado de necesidad habitacional[...]". República de Cuba, Tribunal Supremo Popular, Sentencia 433 del 25 de mayo de 2007, Sala de lo civil y lo administrativo, M. P. Andrés Bolaño Gassó.

16 "[...] pues denunciada la infracción por falta de aplicación de lo dispuesto en la pleca segunda de la Disposición transitoria tercera en relación con el artículo 64 de la Ley general de la vivienda con el argumento de que los actores convivían en el inmueble de la litis en el año 1986, o sea antes de entrar en vigor la señalada norma sustantiva, no puede alcanzar el éxito deseado, porque aun dado por sentada tal afirmación, lo cierto es que el fallecimiento de la titular del inmueble, ocurrió el 17 de junio de 2001 y la transmisión de la titularidad el 29 de diciembre de 2008 [...], lo que hace evidente que lo pretendido es conferirle efectos ultractivos a dicha norma que por su carácter transitorio está destinada a resolver la situación de hecho que acontecía en aquel instante, y que no es la actual [...]". República de Cuba, Tribunal Supremo Popular, Sentencia 1088 del 5 de noviembre de 2014, Sala de lo civil y lo administrativo, M. P. Carlos Manuel Díaz Tenreiro.

17 República de Cuba, Tribunal Supremo Popular, Sentencia 849 del 31 de julio de 2014, Sala de lo civil y lo administrativo, M. P. Carlos Manuel Díaz Tenreiro.

18 "[...] resulta endeble por improcedente y contradictoria, la argumentación que también sostiene para brindar protección a la no recurrente, partiendo de derechos que está reclamando por las aportaciones que hiciera en inmuebles que anteriormente ocupara con el accionante, pues ello no enerva la realidad jurídica actual, que tiene plena virtualidad ante el derecho de propiedad de raigambre constitucional de mayor validez y alcance [...]". República de Cuba, Tribunal Supremo Popular, Sentencia 1034 del 26 de agosto de 2014, Sala de lo civil y lo administrativo, M. P. Carlos Manuel Díaz Tenreiro. 
titular o a cargo de la comunidad matrimonial de bienes y otros casos análogos que decida el presidente de ese Instituto.

Estos casos configuran el argumento esgrimido para mantener la ocupación y a ello se suma que la "injusticia o el acto inhumano" —valoraciones puramente subjetivas- pueden ser efectivamente evaluados en forma distinta por el tribunal que conozca el asunto en cuestión, sin que exista un parámetro uniforme sobre en qué caso se puede o no poner de manifiesto una injusticia.

A criterio del autor, en estos eventos podrían ser incluidas aquellas personas más vulnerables del núcleo familiar a sufrir las consecuencias del cese de convivencia, como los cónyuges, los hijos menores de edad y los ancianos.

\subsection{Dirección Municipal de la Vivienda}

Como lo refleja el Artículo 64, si el conviviente pretendiera permanecer en la vivienda contra la voluntad de su propietario, la Dirección Municipal de la Vivienda dictará resolución, a solicitud de este, si procediera, para conminarlo a abandonar la vivienda en un plazo de treinta días naturales siguientes a la fecha de su notificación. Una vez transcurrido el término, sin que el conviviente deje la vivienda, comunicará a las entidades en las que todos los integrantes del núcleo del conviviente en cuestión reciben sus ingresos acerca de su obligación de hacer un descuento mensual por concepto de uso no autorizado del inmueble, equivalente a un $30 \%$ de cada ingreso. De mantenerse esa situación por tres meses, las retenciones se elevarán a un 50 \% mientras dure la ocupación de la vivienda. Las cantidades producto de estas retenciones se ingresarán al presupuesto del Estado. El objetivo es coaccionar por diferentes medios y de manera progresiva a quien desobedezca lo dispuesto por la Dirección Municipal de la Vivienda.

Las personas de conducta antisocial y no vinculadas laboralmente que se nieguen a ejecutar las disposiciones de la autoridad competente podrán ser obligadas por la policía a cumplirlas.

En la esfera administrativa existen algunas normas que complementan lo establecido en la Ley general de la vivienda: se trata de la Carta Circular 2 de 1985 emitida por el Área de asuntos jurídicos y legislación del Instituto Nacional de la Vivienda y de la Instrucción 4 de 1986 del presidente del Instituto, que resulta muy explicativa. 
Dicha Instrucción aclara que las solicitudes de los propietarios a la Dirección Municipal de la Vivienda para que comunique a los convivientes que deben abandonar la vivienda de aquellos serán tramitadas, en lo pertinente, de acuerdo con las reglas establecidas en la Sección Tercera del Capítulo X de la Ley general de la vivienda. Además, deberán contener, entre otros, lo siguiente: nombre y apellidos de los convivientes; grado de parentesco con el promovente, si lo hubiera; fecha desde cuando ocupan la vivienda e identificación de la entidad en la que laboran los convivientes y su dirección.

El promovente deberá acreditar su condición de propietario, para lo cual deberá acompañar el escrito de solicitud con una copia simple, certificada o fotostática de la escritura o del título de propiedad de la vivienda y estará obligado a exhibir el original cuando lo exija la Dirección Municipal de la Vivienda. En los casos en que el propietario no acredite su titularidad, se archivará el expediente, mediante providencia, hasta que se acredite este particular.

Si, una vez emplazado, el conviviente no contesta la reclamación verbalmente o por escrito o, tras contestar no alega estar incluido en las excepciones previstas por ley o no impugna la condición de propietario del promovente, la Dirección Municipal de la Vivienda dictará resolución sin más trámite en la forma que dispone la Instrucción, según el caso del que se trate.

Si el conviviente arguye pertenecer a los casos de excepción o impugna la condición de propietario del promovente, se abre el procedimiento a prueba en la forma que dispone la ley. Si las Direcciones Municipales de la Vivienda comprueban que la acción que pretende ejercer el propietario va dirigida contra personas amparadas por las excepciones, dictará resolución que derogue la solicitud.

Transcurridos los términos anteriores, si los convivientes no hubieran abandonado la vivienda en cuestión, la Dirección Municipal de la Vivienda, a solicitud del propietario, recabará de la Policía Nacional Revolucionaria que proceda a la extracción de dichos convivientes, para lo cual deberá dirigir escrito firmado por el director a la unidad correspondiente de la Policía Nacional Revolucionaria, con día y hora para la referida extracción, así como los funcionarios autorizados a intervenir. La Dirección Municipal de la Vivienda coordinará con la unidad de la Policía Nacional Revolucionaria cualquier detalle necesario. 
Ante las viviendas afectadas por la Ley de reforma urbana, del 14 de octubre de 1960, la acción de los propietarios no podrá ejercerse contra personas que las ocupaban desde antes de promulgarse la citada ley.

Previo a que la Ley general de la vivienda fuera modificada por el Decreto-Ley 322 de 2014, no procedía recurso alguno en lo administrativo ni en lo judicial contra las resoluciones que dictaba la Dirección Municipal de la Vivienda para conminar a los convivientes a abandonar la vivienda, decretar el embargo o denegar la solicitud del promovente. No obstante, dichas resoluciones podían ser objeto de revisión por el presidente del Instituto Nacional de la Vivienda, según la Disposición especial decimoquinta de la Ley general de la vivienda.

\subsection{Tribunal Provincial Popular}

La resolución emitida por la Dirección Municipal de la Vivienda podía ser impugnada por las partes inconformes ante la Sala de lo Civil y lo Administrativo del Tribunal Provincial Popular. Así lo instituye la Ley general de la vivienda:

[... ] corresponderá a la Sala de lo Civil y de lo Administrativo de los Tribunales Provinciales Populares conocer las reclamaciones contra lo resuelto por las Direcciones Municipales de la Vivienda y Planificación Física, salvo en los casos de ocupantes ilegales, mediante los trámites que regula la Ley procesal correspondiente. En los casos de conflictos como consecuencia de reconocimiento, concesión o reclamación de derechos serán partes del proceso judicial las que lo fueron en el proceso administrativo, además de la administración demandada. ${ }^{19}$

Luego, será de aplicación la Ley 7 de 1977 —Ley de procedimiento civil, administrativo, laboral y económico-, en especial su Segunda Parte, que regula el procedimiento administrativo (arts. 654-695).

El proceso de cese de convivencia es uno de los que más se tramitan en el Tribunal Provincial de Matanzas y ello está en estrecha relación con la cantidad de población que reside en la provincia, lo que a su vez se traduce en un fondo habitacional potencial para generar conflictos. Un análisis de 47 sentencias (tomadas al azar y sin un orden específico) de este órgano judicial, correspondientes al año 2015,

19 Asamblea Nacional del Poder Popular de la República de Cuba, Ley 65 de 1988, "Ley general de la vivienda" (La Habana: Gaceta Oficial núm. 3, 23 de diciembre de 1988), art. 123. 
muestra que el municipio cabecera y Cárdenas son los territorios que presentan una tendencia al aumento de este tipo de proceso. En un segundo grupo se ubican Colón, Jovellanos y Jagüey Grande, mientras Pedro Betancourt, Limonar, Unión de Reyes y Los Arabos fueron las demarcaciones con menos procesos. Respecto a localidades como Martí, Calimete y Perico, las sentencias escogidas no los reflejó, lo que no quiere decir que en esos lugares no existan procesos de esta índole.

En cuanto a los grupos vulnerables, los menores de edad se vieron involucrados en más de un $20 \%$ de los casos, las personas de la tercera edad, en casi un $9 \%$ y los cónyuges (ya sea por matrimonio formalizado o unión de hecho) estaban presentes en más de un $36 \%$ de las situaciones. Estos indicadores refuerzan la idea de que es necesaria una intervención previa de mediación en la familia en aras de preservarla, debido al elevado interés que para la sociedad tiene esta célula fundamental. Llama la atención que los niños representan una cifra importante de sentencias. Otras circunstancias, que no son de interés para esta investigación, en la impugnación de resoluciones de las Direcciones Municipales de la Vivienda en el Tribunal Provincial Popular representan un 34 \% de las sentencias escogidas.

¿Cuáles han sido los pronunciamientos significativos de esta instancia judicial cuando se han visto involucrados los grupos vulnerables? Sobre las personas de la tercera edad resulta muy interesante la Sentencia 32, del 11 de marzo de 2015, cuando menciona:

[... c conforme a la situación fáctica incuestionablemente acreditada y partiendo del principio de justicia social que debe guiar siempre nuestra actuación, merece amparo judicial la demandante, persona de la tercera edad, que por ende requiere de tranquilidad y sosiego, quien no tiene iguales oportunidades de trabajo, actividad social y capacidad de socialización que su contrario en el debate, a cuyo favor tributan los principios a favor las Personas Mayores o de la Tercera Edad ponderados por la Asamblea General de las Naciones Unidas y absolutamente respetados en nuestro país, en cuanto a tener acceso a una vivienda adecuada y a poder residir en su propio domicilio por tanto tiempo como sea posible, en aras de garantizar una vejez tranquila, máxime si habitacionalmente fue a ella a quien amparó el titular anterior del predio; de forma que se impone situación distinta a la apreciada por la entidad 
administrativa actuante, que amerita a la Sala en cumplimiento de su función revisora del actuar administrativo, modificar la resolución que se impugna [... ..$^{20}$

Respecto a niños involucrados, se cita un fragmento de la Sentencia 51 de 30 de marzo de 2015:

[...] ha quedado acreditado con lo actuado en la instancia y con el resultado de las pruebas practicadas ante esta Sala, que a pesar de los años de convivencia de la actora en la vivienda en litis y sus hijos habidos durante el matrimonio con el demandado, persisten otro lugar de residencia a favor de la reclamante, que lo es la vivienda en la que residen sus padres [...] en la que podrá morar a pesar de las carencias que advirtió en su escrito de contestación ante la instancia administrativa, por no constituir impedimento para limitar las prerrogativas concedidas al titular de la vivienda, sobre todo cuanto la actora es una persona joven y con aptitud para el trabajo, y por ello puede, a partir de su esfuerzo y recursos propios y los de sus familiares, menguar esas dificultades, y por otro lado, encaminar, con apoyo del demandado, un proceso de adaptación para sus hijos, sobre los que ostenta la guarda y cuidado, de la manera menos perjudicial y traumática para ellos, teniendo en cuenta que el proceso que se ventila no guarda relación alguna con estos, y que tal cuestión de orden paterno filial no puede usarse para obligar al titular demandado de la vivienda a mantener una convivencia no deseada con la actora. ${ }^{21}$

Para finalizar el análisis sobre el Tribunal Provincial Popular de Matanzas, se expone un fragmento de la Sentencia 89, del 30 de abril de 2015, referente a los cónyuges como grupo afectado por el proceso de cese de convivencia:

[... que la inconforme posee otro lugar donde residir que lo es la vivienda que ocupa su señora madre, [...] a lo que ha de sumársele el hecho de que la demandante es una persona joven, en plenitud de sus facultades, y con aptitud

$20 \quad$ En ese mismo sentido está el tercer considerando: "Que independientemente del tiempo de residencia de la actora en esta vivienda, ello no le otorga derechos diferentes al de resultar una simple conviviente, cuya coexistencia en él puede ultimar el titular del predio al no existir razones contundentes para limitar su potestad [...], generándose indudablemente con su presencia en el recinto como conviviente indeseada, una situación insostenible para el titular del predio, quien es por demás una persona anciana y enferma, que solicita la tranquilidad necesaria para su vida en el hogar, el que señala se vio precisado a abandonar por las discrepancias con la demandante [...]". República de Cuba, Tribunal Supremo Popular, Sentencia 156 del 25 de octubre de 2015, Sala de lo civil y administrativo, M. P. no especificado.

21 República de Cuba, Tribunal Supremo Popular, Sentencia 51 de 30 de marzo de 2015, Sala de lo civil y lo administrativo, M. P. no especificado. 
para el trabajo, y por ello puede, a partir de su esfuerzo y recursos propios y los de sus familiares, menguar las carencias anunciadas del inmueble de su madre o sencillamente obtener otra; y [...] unido a que por sentencia dictada por esta propia Sala en expediente de apelación fuera reconocido como un matrimonio no formalizado la unión de pareja que sostuvieron las partes, extremo ese último que no le concede el derecho a la convivencia que se discute, mientras no acredite ostentar un derecho superior, a saber la propiedad sobre el inmueble, el que hasta la fecha está expectante al resultado del proceso administrativo que advirtió a la Sala que se sustancia por la inconforme ante la autoridad administrativa competente. ${ }^{22}$

Luego, es notoria la necesidad de reforzar una solución alternativa al proceso de cese de convivencia en aras de proteger a los individuos que son más afectados. Sería la mediación en sede familiar una solución conveniente a aplicar, pero ese es tema para otra investigación.

\subsection{Tribunal Supremo Popular}

De acuerdo con el Artículo 123 de la Ley general de la vivienda, conforme a la legislación vigente, contra lo resuelto por los tribunales provinciales populares procede recurso de casación ${ }^{23}$ ante la sala competente del Tribunal Supremo Popular. La competencia del TSP está regulada en el precepto 665 de la Ley de procedimiento civil, administrativo, laboral y económico.

Ahora es necesario referirse a la Instrucción 230 de 2014, del Consejo de Gobierno del Tribunal Supremo Popular; si bien no alude al cese de convivencia, fue dictada con motivo de las modificaciones que introdujo el Decreto-Ley 322 de $2014 .^{24}$ Esas modificaciones, como se expresa en uno de los Por cuanto de la Instrucción, tienen directa incidencia en la tarea de los órganos jurisdiccionales de la materia administrativa — que hasta el momento habían conocido los procesos de dicha jurisdicción en los que se impugnaban resoluciones dictadas por las entidades del

22 República de Cuba, Tribunal Provincial Popular de Matanzas, Sentencia 89 del 30 de abril de 2015, Sala de lo civil, administrativo y laboral.

23 República de Cuba, Tribunal Supremo Popular, Sentencia 971 del 31 de octubre de 2016, Sala de lo civil y lo administrativo, M. P. Carlos Manuel Díaz Tenreiro.

24 El Decreto-Ley 322 de 2014 modificó los artículos 4, 13, 15, 16, 17, 18, 19, 21, 22, 24, 34, 61, 62, 63, $67,73,74,108,109,122,123,124,126,127,128,129,130,137,138$ y 145 de la Ley general de la vivienda. Presidencia de la República de Cuba, Decreto Ley 322 de 2014, "Modificativo de la Ley 65 de 23 de diciembre de 1988, Ley general de la vivienda" (La Habana: Gaceta Oficial núm. 40, 5 de septiembre de 2014), art. 1. 
sistema de la vivienda - por la transferencia de funciones al Instituto de Planificación Física y a los tribunales populares en la jurisdicción civil.

La Instrucción es bastante explicativa y de ella el autor de esta investigación desea resaltar el punto 2 del apartado 5: al examinar las demandas, los Tribunales velarán porque en los hechos se consigne con claridad la composición de los núcleos familiares que ocupan los inmuebles objeto de la permuta y la forma como quedarían organizados una vez se realice esta y que se especifique si hay discapacitados, menores de edad o enfermos crónicos; ello evidencia un marcado enfoque del derecho de familia para tutelar los derechos de los individuos más vulnerables.

Uno de los criterios más reiterados por este Alto Foro consiste en que:

[...] para impugnar el fondo de la sentencia recurrida en casación, viene obligado el recurrente a respetar los supuestos de hecho en que descansa la misma, sin contradecirlos, y al afirmar otros en contrario, al plantear su concepto de infracción sobre la base de que no cuenta otro lugar donde residir, se proyecta en contra de la naturaleza de la causal invocada lo que hace que se rechacen los motivos estudiados [...]..$^{25}$

\section{A modo de conclusiones}

La familia sigue siendo la célula fundamental de toda sociedad y por tanto es indispensable profundizar en el análisis sociológico y jurídico de sus nuevas formas, para comprender los esquemas que se han estructurado. Las controversias asociadas con la vivienda cobran especial relevancia en Cuba, dado el déficit habitacional existente; ejemplo de ello lo constituye el proceso de cese de convivencia, que exacerba las situaciones conflictivas. Se trata de una de las tramitaciones litigiosas de más presencia en los tribunales populares, sobre todo en la provincia de Matanzas, por lo que debe ser objeto de un examen integral.

El proceso de cese de convivencia, que es tramitado ante la Sala de lo Civil y lo Administrativo de los tribunales cubanos, carece de un análisis propio, si se parte de que en muchos casos los litigios involucran grupos familiares consolidados o en vías de hacerlo. Urge repensar este proceso, puesto que las soluciones alternativas

25 Ejemplo tomado del segundo considerando. República de Cuba, Tribunal Supremo Popular, Sentencia 1119 del 10 de septiembre de 2014, Sala de lo civil y lo administrativo, M. P. Carlos Manuel Díaz Tenreiro. 
como la mediación familiar pueden contribuir con más efectividad a la respuesta no adversarial a un conflicto asociado con la vivienda.

Un enfoque familiar es un medio fundamental para resolver beligerancias desde una óptica mucho más amplia, pues permite sondear los problemas puntualmente, aspecto que en el ámbito administrativo-judicial es difícil por el sistema implementado. El lenguaje adversarial del litigio no solo resulta contradictorio con la necesidad de restablecer la comunicación en la unidad, sino que puede fracturar en forma definitiva las relaciones familiares.

\section{Referencias}

Aguirre Alonso, Raisa María. "La jurisprudencia como fuente de derecho". Justicia y derecho, núm. 26 (junio 2016): 121-134. http://www.tsp.gob.cu/sites/default/files/revista/doc umento/26justiciaderechoespecial_0.pdf (acceso mayo 17, 2018).

Asamblea nacional del poder popular de la República de Cuba. Ley 65 de 1988, "Ley general de la vivienda". La Habana: Gaceta Oficial núm. 3, 23 de diciembre de 1988.

Cabanellas, Guillermo. Diccionario enciclopédico de derecho usual. 21 a ed., tomo 3. Buenos Aires: Heliasta, 1989.

Herrera, Marisa. "Distintas formas de organización familiar" en Manual de derecho de las familias, editado por Marisa Herrera, 17-26. Buenos Aires: Abeledo Perrot, 2015.

Ortega García, Erick. "La ocupación de viviendas como categoría legal, a partir de las modificaciones introducidas en el derecho inmobiliario cubano". Misión jurídica, núm. 7 (enero-diciembre 2014): 83-99. https://www.revistamisionjuridica.com/wp-content/ uploads/2017/03/La-ocupaci\%C3\%B3n-de-viviendas-como-categor\%C3\%ADa-legala-partir-de-las-modificaciones-introducidas-en-el-derecho-inmobiliario-cubano.pdf (acceso mayo 15, 2018).

Partido Comunista de Cuba. Documentos del 7 mo. congreso del Partido aprobados por el III pleno del Comité Central del PCC el 18 de mayo de 2017 y respaldados por la Asamblea nacional del poder popular el 1 de junio de 2017-I. La Habana: UEB Gráfica, 2017.

Presidencia de la República de Cuba. Decreto Ley 322 de 2014, "Modificativo de la Ley 65, de 23 de diciembre de 1988, Ley general de la vivienda". La Habana: Gaceta Oficial núm. 40, 5 de septiembre de 2014.

República de Cuba, Tribunal Provincial Popular de Matanzas, Sentencia 89 del 30 de abril de 2015, Sala de lo civil y administrativo.

República de Cuba, Tribunal Supremo Popular. Sentencia 1034 del 26 de agosto de 2014. Sala de lo civil y lo administrativo. M. P. Carlos Manuel Díaz Tenreiro. 
República de Cuba, Tribunal Supremo Popular. Sentencia 1088 del 5 de noviembre de 2014. Sala de lo civil y lo administrativo. M. P. Carlos Manuel Díaz Tenreiro.

República de Cuba, Tribunal Supremo Popular. Sentencia 1119 del 10 de septiembre de 2014.

Sala de lo civil y lo administrativo. M. P. Carlos Manuel Díaz Tenreiro.

República de Cuba, Tribunal Supremo Popular. Sentencia 1244 del 10 de diciembre de 2010.

Sala de lo civil y lo administrativo. M. P. Carlos Manuel Díaz Tenreiro.

República de Cuba, Tribunal Supremo Popular. Sentencia 1449 del 24 de noviembre de 2014.

Sala de lo civil y lo administrativo. M. P. Carlos Manuel Díaz Tenreiro.

República de Cuba, Tribunal Supremo Popular. Sentencia 147 del 28 de febrero de 2005. Sala

de lo civil y lo administrativo. M. P. Isabel Arredondo Suárez.

República de Cuba, Tribunal Supremo Popular. Sentencia 156 del 25 de octubre de 2015.

Sala de lo civil y lo administrativo. M. P. no especificado.

República de Cuba, Tribunal Supremo Popular. Sentencia 30 del 15 de octubre de 2012. Sala

de lo civil y lo administrativo. M. P. Orlando González García.

República de Cuba, Tribunal Supremo Popular. Sentencia 324 del 10 de abril de 2008. Sala

de lo civil y lo administrativo. M. P. Orlando González García.

República de Cuba, Tribunal Supremo Popular. Sentencia 384 del 28 de abril del 2000. M.

P. Marta Acosta Ricart.

República de Cuba, Tribunal Supremo Popular. Sentencia 433 del 25 de mayo de 2007. Sala de lo civil y lo administrativo. M. P. Andrés Bolaño Gassó.

República de Cuba, Tribunal Supremo Popular. Sentencia 51 del 30 de marzo de 2015. Sala de lo civil y lo administrativo. M. P. no especificado.

República de Cuba, Tribunal Supremo Popular. Sentencia 555 del 17 de mayo de 2011. Sala de lo civil y lo administrativo. M. P. Orlando González García.

República de Cuba, Tribunal Supremo Popular. Sentencia 849 del 31 de julio de 2014. Sala de lo civil y lo administrativo. M. P. Carlos Manuel Díaz Tenreiro.

República de Cuba, Tribunal Supremo Popular. Sentencia 971 del 31 de octubre de 2016. Sala de lo civil y lo administrativo. M. P. Carlos Manuel Díaz Tenreiro.

Rojas, María del Carmen. "La vulnerabilidad y el riesgo de la vivienda para la salud humana desde una perspectiva holística. Una revisión necesaria para la gestión de la vivienda saludable". Cuaderno urbano 4, núm. 4 (diciembre 2004): 145-174. http://revistas. unne.edu.ar/index.php/crn/article/view/1763/1517 (acceso mayo 21, 2018). 